\title{
Cardiovascular System Findings Planned End of Assessment Interval
}

National Cancer Institute

\section{Source}

National Cancer Institute. Cardiovascular System Findings Planned End of Assessment

Interval. NCI Thesaurus. Code C123961.

The period of time that the cardiovascular system assessment, done over an interval of time, is intended to finish. 